\title{
Titanium and Chromium Determination in Feedstuffs Using ICP-AES Technique
}

\author{
Eleni Tsanaktsidou and George Zachariadis *(D) \\ Laboratory of Analytical Chemistry, Department of Chemistry, Aristotle University, 54124 Thessaloniki, Greece; \\ eltsanaktsidou@yahoo.com \\ * Correspondence: zacharia@chem.auth.gr; Tel.: +30-231-099-7707
}

Received: 13 October 2019; Accepted: 17 December 2019; Published: 20 December 2019

check for updates

\begin{abstract}
The present study represents the determination of Ti and $\mathrm{Cr}$ in dry animal feeds using wet acid digestion and inductively coupled plasma-atomic emission spectrometry (ICP-AES), in order to use these metals as digestibility markers. A radiofrequency power of $1350 \mathrm{~W}$ and a nebulizer argon flow of $0.8 \mathrm{~L} / \mathrm{min}$ was selected. The limits of detection were between 11.4 and $16.1 \mu \mathrm{g} / \mathrm{g}$ for titanium and between 10.7 and $38.2 \mu \mathrm{g} / \mathrm{g}$ for chromium. The recovery values for the aqueous solutions were 89.5-103.9\% (titanium) and $85.3-104.2 \%$ (chromium), with relative standard deviations (RSD\%) under $2.1 \%$ and standard errors under $2.32 \%$, demonstrating that the method offered good accuracy and repeatability. Six different samples of commercially available feedstuffs (two cat foods, two dog foods, and two poultry foods) were analyzed and the levels of investigated metals were found to be in the ranges of $0.10 \mathrm{~g} / \mathrm{kg}$ and $<\mathrm{LOD}$ for chromium and titanium, respectively (dog foods); $0.10-0.18 \mathrm{~g} / \mathrm{kg}$, $0.70 \mathrm{~g} / \mathrm{kg}$ for chromium and titanium, respectively (cat foods); and $0.07 \mathrm{~g} / \mathrm{kg}, 0.82-1.35 \mathrm{~g} / \mathrm{kg}$ for chromium and titanium, respectively (poultry foods).
\end{abstract}

Keywords: feedstuffs; titanium; chromium; ICP-AES

\section{Introduction}

In recent years, the population of pets has grown, resulting in the increase of the production of pet food [1]. Therefore, products for dogs, cats, and birds are widely available on the market in a variety of shapes and flavors, including dry and wet products, canned food, and treats, offering the owners a wide variety of options regarding what is suitable for their pets according to their age, breed, and size. Feeds could be a single ingredient pet food, or a product of high complexity, containing over 60 ingredients [1].

Food intake is crucial information for evaluating the nutritional status of animals. An indirect, safe, and easy method to evaluate the nutritional status or the digestibility of feed through the gut is by using external markers. In order to conduct a digestibility study and measure digestive kinetics, the usual procedure is to measure indigestible exogenous dietary markers such as chromium, ytterbium, titanium, and cobalt both in dry feed matter intake and in dry fecal matter output [2]. This study focused on the determination of the total concentrations of the most common exogenous markers in dry feedstuffs, chromium and titanium. Titanium dioxide $\left(\mathrm{TiO}_{2}\right)$ is considered a biologically inactive compound [3], and it can be added to feedstuff as an external marker for different animal species [2,4-9]. Additionally, $\mathrm{TiO}_{2}$ (E171) can be legally used as a color additive to food, which signifies the safety of its use in animal diets [10]. Chromium in form of chromic oxide $\left(\mathrm{Cr}_{2} \mathrm{O}_{3}\right)$ used to be the most common marker for digestibility studies $[2,8,9,11,12]$. Additionally, $\mathrm{Cr}$ in form of chromium propionate (Cr-Prop) is FDA-approved as a supplement for animals, since $\mathrm{Cr}^{3+}$ species are classified as an essential metal for their crucial role in glucose metabolism, body weight control, protein metabolism, and increased milk production in dairy cows [13,14]. 
Most digestibility studies that have been published to date refer to ruminants, but to the best of our knowledge, no published research concerns digestibility studies regarding pets. For this reason, the present study focused on the measurement of $\mathrm{Ti}$ and $\mathrm{Cr}$, which are both viable markers, in pet food. Generally, the present study used an analytical method for the simultaneous determination of the total concentration of $\mathrm{Ti}$ and $\mathrm{Cr}$ in pet feedstuffs, using the inductively coupled plasma-atomic emission spectrometry (ICP-AES) technique.

Quantitative chemical analysis of solid samples demands sample pretreatment to make the sample compatible with the used technique. This could include digestion or extraction of the analytes followed by instrumental analysis. Among the most frequent sample preparation techniques for food and animal food analysis using spectroanalytical methods such as ICP-AES are dry ashing and wet acid digestion [15]. Wet acid digestion is an appropriate method for sample pretreatment in order to achieve complete decomposition and dissolution of biological samples, food, and feedstuffs. Improvements in sample preparation techniques have recently focused on the rapidity of the procedure, as well as the simplicity and need for smaller volumes of oxidants [16-18]. However, the efficiency of the digestion is also influenced by the temperature within the reaction vessel [18] and the acids employed. According to the literature on this topic, wet acid digestion is one of the most common techniques for sample pretreatment of feedstuffs. For example, for the determination of elemental composition of dog food in one study, microwave assisted nitric acid digestion was used, compared to a simulated gastric acid digestion and followed by ICP-MS analysis [19]. In order to determine Ti concentration in feeds, feces, and ileal digesta, an appropriate mixture of sulfuric acid and nitric acid was prepared for ICP-OES analysis [6]. For the comparison of two analytical methods for the determination of $\mathrm{TiO}_{2}$, an aqua regia digestion step (mixture of nitric acid and hydrochloric acid) prior the ICP-OES assay was reported [20]. In another work, for the determination of $\mathrm{Cr}$ in dry cattle food, a mixture of nitric acid and hydrogen peroxide was used before ICP-MS analysis [21]. It is clear that the conventional approach for wet digestion is the use of inorganic acid mixtures. It is worth mentioning that the use of formic acid has also been proposed as a way to completely extract macro- and microelements from feedstuff samples using ICP-OES [22].

Determination of metals in high-carbon-content samples can be done using techniques that enable simultaneous multielement analysis, such as atomic emission spectrometry (AES) or mass spectrometry (MS), both coupled with inductively coupled plasma (ICP) for analyte atomization [23-26]. Furthermore, ICP-AES analysis offers a wide range of applications along with high sensitivity, and it is considered to be almost free of important spectral interferences [23].

Based on the above studies, in the present work, the use of a wet acid digestion method was employed for the complete decomposition of dry feedstuff prior to the chemical analysis of the samples using an ICP-AES technique. The additional feature and main purpose of the study was to simultaneously determine the total $\mathrm{Cr}$ and Ti content in dry feedstuffs for pets available on the market, and also in spiked feedstuff samples to which precise amount of titanium and chromium had been added. The method can be applied to monitoring of titanium or chromium levels by ICP-AES technique when used as external markers during digestibility studies.

\section{Materials and Methods}

\subsection{Instrumentation}

All measurements were carried out using an axial viewing plasma spectrometer, Perkin Elmer Optima 3100 XL model, according to the operating conditions described in Table 1. 
Table 1. Instrumental parameters and measurement conditions.

\begin{tabular}{|c|c|c|c|}
\hline \multicolumn{4}{|c|}{ Instrumental Parameters } \\
\hline Parameter & \multicolumn{3}{|c|}{ Value } \\
\hline Radiofrequency $(\mathrm{RF})$ generator & \multicolumn{3}{|c|}{$40 \mathrm{MHz}$, free-running } \\
\hline RF incident power & \multicolumn{3}{|c|}{$1350 \mathrm{~W}$} \\
\hline Torch type & \multicolumn{3}{|c|}{ Fassel type } \\
\hline Injector, id & \multicolumn{3}{|c|}{ Alumina, $2.0 \mathrm{~mm}$} \\
\hline Viewing mode & \multicolumn{3}{|c|}{ Axial } \\
\hline Auxiliary argon flow rate & \multicolumn{3}{|c|}{$0.50 \mathrm{~L} \mathrm{~min}^{-1}$} \\
\hline Nebulizer & \multicolumn{3}{|c|}{ Gem tip cross flow } \\
\hline Plasma gas flow rate & \multicolumn{3}{|c|}{$15 \mathrm{~L} \mathrm{~min}^{-1}$} \\
\hline Spray chamber type & \multicolumn{3}{|c|}{ Scott-double pass } \\
\hline Polychromator & \multicolumn{3}{|c|}{ Echelle grating } \\
\hline Sample propulsion & \multicolumn{3}{|c|}{ Peristaltic pump, three channel } \\
\hline Sample uptake flow rate & \multicolumn{3}{|c|}{$2 \mathrm{~mL} \mathrm{~min}^{-1}$} \\
\hline Detector & \multicolumn{3}{|c|}{ Segmented-array charge-coupled (SCD) } \\
\hline Delay time & \multicolumn{3}{|c|}{$30 \mathrm{~s}$} \\
\hline \multicolumn{4}{|c|}{ Measurement Conditions } \\
\hline Analyte & \multicolumn{3}{|c|}{ Spectral line (nm) } \\
\hline $\mathrm{Ti}$ & 334.940 & 337.279 & 368.519 \\
\hline $\mathrm{Cr}$ & 283.563 & 357.869 & \\
\hline
\end{tabular}

The injector used was constructed of alumina, which offers resistance to acidified solutions. A peristaltic pump was employed to introduce the sample solutions into the ICP-AES at a flow rate of $2 \mathrm{~mL} \mathrm{~min}{ }^{-1}$, and to discard the wastes at a higher flow rate. Tygon-type PVC peristaltic pump tubes (i.d.0.030 in) were used to introduce feedstuff sample solutions. A cyclonic spray chamber with a cross-flow nebulizer was employed to allow higher rates of sample introduction into the plasma. The analytical wavelengths selected for each analyte are listed in Table 1.

\subsection{Reagents and Standard Solutions}

All reagents were of analytical grade (pro analysis). Concentrated $\mathrm{HNO}_{3}(65 \%)$, concentrated $\mathrm{HCl}(37 \%)$ and concentrated $\mathrm{H}_{2} \mathrm{SO}_{4}(95-97 \%)$, used for wet digestion, were also of analytical grade and were provided by Merck (Darmstadt, Germany). Ultrapure water of Milli-Q quality (Millipore, Bedford USA, with $18.2 \mathrm{M} \Omega . \mathrm{cm}$ resistivity at $25^{\circ} \mathrm{C}$ ) was used throughout the study. Chemical reagents used for preparation of standard solutions were of analytical grade (Merck). A working standard solution was prepared by mixing suitable aliquots of single-element stock solutions each containing $\mathrm{Ti}$ and $\mathrm{Cr} 1000 \mathrm{mg} \mathrm{L}^{-1}$ (Merck) after having subjected to appropriate dilutions. All solutions were stored in polyethylene bottles in the refrigerator. During the 1 month storage in a refrigerator no precipitation or turbidity was observed by visual inspection. In addition, a calibration test of the multi-element standard against a freshly prepared sample showed no significant analyte changes. Thus, the multi-element standard can be used throughout a 1 month period without causing any bias in the calibration procedure. Finally, five point calibration curves were obtained using aqueous multi-element standards. The final mixed working standard solutions had the following concentrations: $0.00,0.25$, $1.00,5.00$, and $10.00 \mathrm{mg} \mathrm{L}^{-1}$ for each metal. The slope of the regression lines was used to estimate the sensitivity of the method in all cases. For the preparation of standard solutions, titanium in the form of titanium dioxide provided by BDH Chemicals (mixture of anatase and rutile phase) and chromium in the form of $\mathrm{Cr}\left(\mathrm{NO}_{3}\right)_{3} \cdot 9 \mathrm{H}_{2} \mathrm{O}$ were used, provided by Merck.

\subsection{Sample Collection}

Six different samples of dry feeds, which are coded as AFS (AFS: animal feedstuffs) in this study, were collected from the markets in Thessaloniki, Greece and analyzed. They were feedstuffs (a) for 
dogs, which are coded as AFS-1 (chicken and vegetables) and AFS-2 (veal and vegetables); (b) for cats, which are coded AFS-3 (chicken and vegetables) and AFS-4 (rabbit, chicken, and vegetables); and (c) for poultry, which are coded AFS-5 (seeds, wheat, and rice) and AFS-6 (corn, soybean, and wheat). According to the package labels, all the feedstuffs were supposed to contain neither chromium nor titanium. Before analysis, the samples were transferred from their package to a porcelain mortar and were ground by hand for $5 \mathrm{~min}$ using a pestle until the feedstuff was completely powdered.

\subsection{Sample Preparation of Dry Feeds}

As previously reported in the literature, the wet acid method is considered to be the most appropriate method for sample preparation of dry feedstuffs. In order to completely decompose the samples, acid attack of the samples was done using a mixture of oxidative acids. Seven acid digestion mixtures were tested and the observations of their effectiveness are shown in Table 2.

Table 2. Dissolution tests ( $0.5 \mathrm{~g}$ of every feedstuff sample was tested, approximate temperatures).

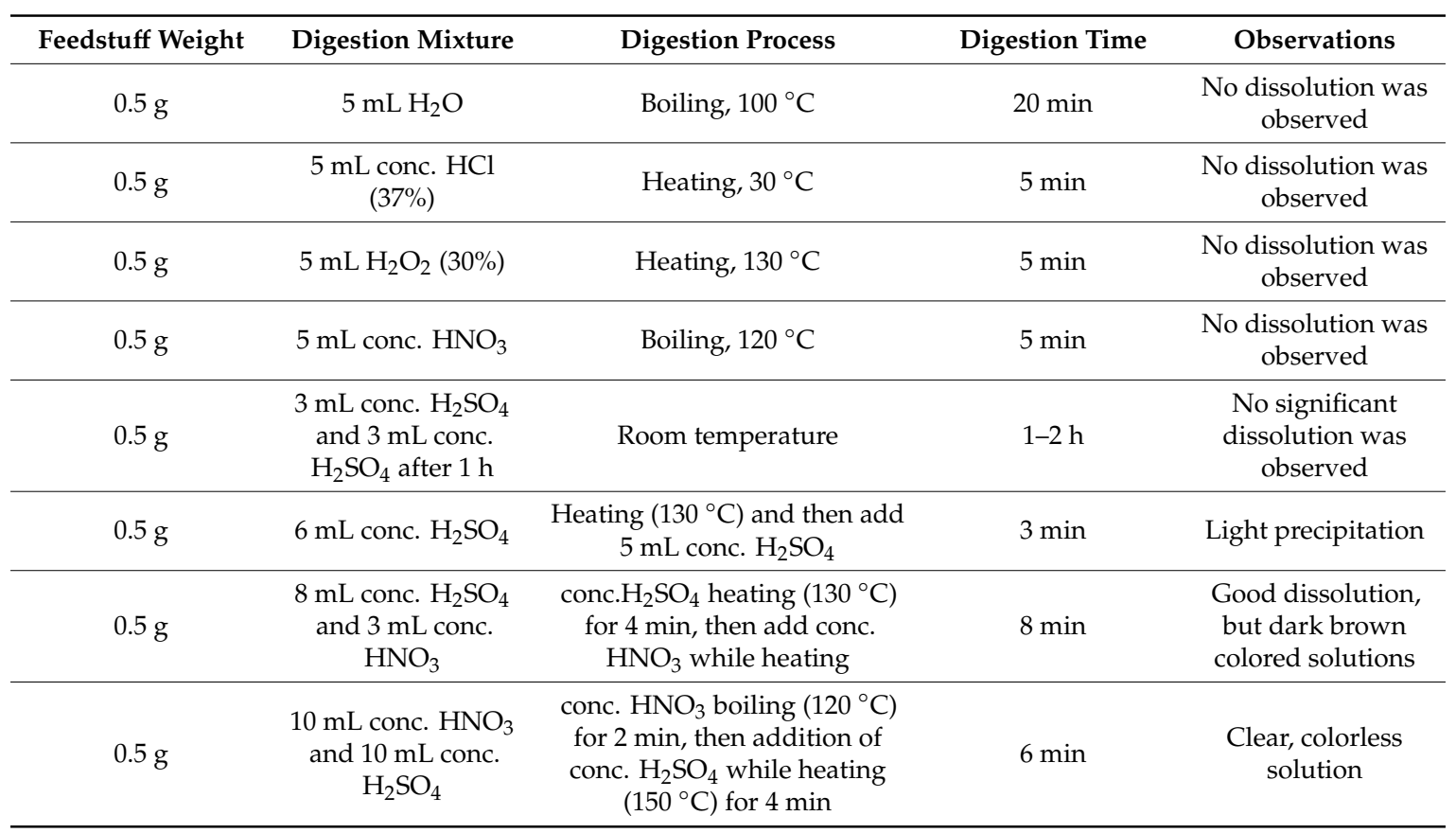

In order to completely dissolve the dry feedstuff samples, it was necessary to use strong oxidative acids like nitric acid and sulfuric acid or a mixture of both. Nitric acid is a widely used reagent for wet digestion of organic and biological materials, because no significant analytical problems are encountered with relatively high concentrations of nitric acid in the ICP atomization system. In addition, sulfuric acid is necessary for the dissolution of refractory element compound of $\mathrm{Ti}$ as $\mathrm{TiO}_{2}$ [23]. Regarding the observations in Table 2, the use of $\mathrm{HCl}$ and $\mathrm{H}_{2} \mathrm{O}_{2}$ was not favorable because no dissolution was observed during the first $5 \mathrm{~min}$, and the most effective acid digestion mixture was the last one. On the other hand, HF acid, which is useful for titanium oxide, was not used in order to avoid damage to the quartz atomizer. The detailed procedure for sample pretreatment and sample preparation is described below. As for the dissolution of $\mathrm{TiO}_{2}$, it is worth mentioning that the possibility of colloidal $\mathrm{TiO}_{2}$ remained, although the digested solution may have become clear and colorless.

Sample portions of $150 \mathrm{mg}$ (dry weight) were weighed out and placed into glass flasks, after which $10 \mathrm{~mL}$ of concentrated nitric acid was added to each flask, the samples were boiled $\left(120^{\circ} \mathrm{C}\right)$ on a plate in strong fume hood for about $2 \mathrm{~min}$, after which the vast amount of organic material was attacked, resulting in a yellow solution and production of thick brown-yellow fumes. Immediately after, $10 \mathrm{~mL}$ sulfuric acid was added while heating for 3-4 min, after which the solution became clear, 
colorless to light yellowish, and the whole sample was dissolved. The final digest was diluted to volume (100 mL volumetric flasks) with milli-Q water. The obtained solution was further diluted at ratios of 1:10 and 1:100 successively, and the analysis was repeated three times for each sample. Blank solutions of the whole method were prepared three times following the same wet acid digestion procedure. In addition, spiked samples were used to obtain the recovery of the method and in order to validate the method for accuracy and precision, alongside aqueous reference solutions for each element. For the preparation of the spiked samples, $50 \mathrm{mg}$ samples of $\mathrm{TiO}_{2}$ and $50 \mathrm{mg}$ of $\mathrm{Cr}\left(\mathrm{NO}_{3}\right)_{3}$ were weighed and mixed with $150 \mathrm{mg}$ of feedstuff samples, and secondly, $0.5 \mathrm{mg}$ of $\mathrm{TiO}_{2}$ and $0.5 \mathrm{mg}$ of $\mathrm{Cr}\left(\mathrm{NO}_{3}\right)_{3}$ followed the same procedure. Finally, the above described procedure was applied and the obtained clear solution was diluted with milli-Q water.

\section{Results and Discussion}

\subsection{Calibration Studies}

The conditions described above were applied in order to establish a five point calibration curve for aqueous standard solutions of the following concentrations: $0.00,0.25,1.00,5.00$, and $10.00 \mathrm{mg} \mathrm{L}^{-1}$ for each metal and each spectral line. Regression analysis was used to estimate the sensitivity of the method, and detailed results are shown in Table 3.

Table 3. Regression analysis of the aqueous standard solutions. Slope ( \pm standard error), intercept (cps), and correlation coefficients $(r)$.

\begin{tabular}{cccccc}
\hline Element & Wavelength $(\mathbf{n m})$ & Slope $(\mathbf{c p s} / \mathbf{( m g} / \mathbf{L}))$ & Intercept (cps) & Standard Error & $r$ \\
\hline \multirow{3}{*}{$\mathrm{Ti}$} & 334.940 & $333 \pm 11$ & 3.8 & 3.59 & 0.9998 \\
& 336.121 & $400 \pm 7$ & 2.3 & 2.32 & 0.9999 \\
& 337.279 & $276 \pm 4$ & 7.0 & 1.39 & 0.9999 \\
& 368.519 & $144 \pm 2$ & 2.0 & 0.79 & 0.9999 \\
\hline \multirow{2}{*}{$\mathrm{Cr}$} & 283.563 & $62 \pm 1$ & 34.0 & 0.31 & 0.9999 \\
& 284.325 & $44.5 \pm 0.7$ & 32.0 & 0.22 & 0.9999 \\
& 357.869 & $118 \pm 3$ & 0.4 & 0.95 & 0.9999 \\
\hline
\end{tabular}

The sensitivity of the method was estimated by the slopes of the linear equations obtained for calibration curves. The selected spectral lines were quite sensitive (higher slopes), especially the lines $334.940 \mathrm{~nm}$ and $336.121 \mathrm{~nm}$ for Ti and $357.869 \mathrm{~nm}$ for $\mathrm{Cr}$, which also had very low intercept values with very good correlation coefficients $(r>0.999)$, and the calculated standard error ranged between 0.22 and 3.59. In addition, in order to test for possible matrix effects, a standard addition procedure was also applied using sample AFS-1. Into $150 \mathrm{mg}$ of AFS-1, amounts of $0.05,0.10,0.5,1.0$, and $5.00 \mathrm{mg}$ of $\mathrm{TiO}_{2}$ and the same for $\mathrm{Cr}\left(\mathrm{NO}_{3}\right)_{3}$ were added. The mixtures were homogenized using a porcelain mortar and pestle. Subsequently, every mixture was digested following the described procedure of wet acid digestion and diluted to volume with milli-Q water. After regression analysis, the obtained slopes were found to be $315 \pm 8$ for Ti at $334.940 \mathrm{~nm}$ and $111 \pm 5$ for $\mathrm{Cr}$ at $357.869 \mathrm{~nm}$, which were in good agreement with the slopes using external standards. Correlation coefficients for both metals were good $(r>0.999)$; the intercept of Ti was equal to 5.2 at $334.940 \mathrm{~nm}$, and that of $\mathrm{Cr}$ was equal to 1.0 at $357.869 \mathrm{~nm}$.

\subsection{Figures of Merit}

The performance of the method was evaluated under the conditions described above. Blank solutions were used to calculate limits of detection (LOD) and limits of quantification (LOQ) for titanium and chromium in dry feedstuff samples. LOD and LOQ were estimated based on the specifications of the International Union of Pure and Applied Chemistry (IUPAC) [27]. The results are given in Table 4 as method equivalent LODs and LOQs (expressed in $\mu \mathrm{g} / \mathrm{g}$ ), considering dry sample masses of 
$150 \mathrm{mg}$ for the analysis and followed by successive dilutions. The LOD for titanium varied between 11.4 and $16.1 \mu \mathrm{g} / \mathrm{g}$, and for chromium between 10.7 and $38.2 \mu \mathrm{g} / \mathrm{g}$, with the variation due to variability of the baseline signal values in different spectral lines. The LOQ varied between $37.5-52.9 \mu \mathrm{g} / \mathrm{g}$ and $36.2-119.9 \mu \mathrm{g} / \mathrm{g}$ for titanium and chromium, respectively.

Table 4. Calculated limits of detection (LOD) and limits of quantification (LOQ), using 10 measurements of blank solutions $(\mu \mathrm{g} / \mathrm{g})$.

\begin{tabular}{cccc}
\hline Element & Wavelength $(\mathbf{n m})$ & LOD $(\mu \mathrm{g} / \mathrm{g})$ & LOQ $(\mu \mathrm{g} / \mathrm{g})$ \\
\hline \multirow{3}{*}{$\mathrm{Ti}$} & 334.940 & 13.4 & 44.9 \\
& 336.121 & 11.4 & 37.5 \\
& 337.279 & 16.1 & 52.9 \\
$\mathrm{Cr}$ & 368.519 & 12.1 & 40.9 \\
\hline \multirow{2}{*}{$\mathrm{Cr}$} & 283.563 & 38.2 & 127.3 \\
& 354.325 & 36.2 & 119.9 \\
\hline
\end{tabular}

In order to estimate the precision and accuracy of the method, calculations of relative standard deviation (RSD) and recovery (R) were used, respectively. The relative standard deviation was calculated using aqueous solutions of specific concentration of titanium and chromium at 0.25, 1.00, 5.00 , and $10.00 \mathrm{mg} / \mathrm{L}$. On the other hand, one dog food (AFS-1), one cat food (AFS-3), and one poultry food (AFS-5) were weighed (150 mg), spiked with $50 \mathrm{mg}$ of $\mathrm{Ti}$ and $50 \mathrm{mg}$ of $\mathrm{Cr}$, and digested as described above. The RSD\% measurements were done by measuring the samples three times on the same day. The results are shown in Table 5. Based on these results, very good repeatability was observed for both metals at almost every selected concentration.

Table 5. Calculated relative standard deviation (RSD\%) of aqueous solutions of the analytes, and spiked feedstuff samples of AFS-1 (dog food), AFS-3 (cat food), and AFS-6 (poultry food), $n=3$.

\begin{tabular}{ccccccccc}
\hline \multirow{2}{*}{ Element } & Wavelength (nm) & \multicolumn{7}{c}{ RSD \% } \\
\cline { 3 - 9 } & & $\begin{array}{c}\mathbf{0 . 2 5} \\
\mathbf{m g} / \mathbf{L}\end{array}$ & $\begin{array}{c}\mathbf{1 . 0 0} \\
\mathbf{m g} / \mathbf{L}\end{array}$ & $\begin{array}{c}\mathbf{5 . 0 0} \\
\mathbf{m g} / \mathbf{L}\end{array}$ & $\begin{array}{c}\mathbf{1 0 . 0 0} \\
\mathbf{m g} / \mathbf{L}\end{array}$ & AFS-1 & AFS-3 & AFS-5 \\
\hline \multirow{3}{*}{$\mathrm{Ti}$} & 334.940 & 0.6 & 0.5 & 1.6 & 0.1 & 2.8 & 2.3 & 2.1 \\
& 336.121 & 0.5 & 0.1 & 1.5 & 1.2 & 2.4 & 2.4 & 2.3 \\
& 337.279 & 1.2 & 0.1 & 1.5 & 1.0 & 2.4 & 2.9 & 2.3 \\
& 368.519 & 1.1 & 0.3 & 1.5 & 1.2 & 2.3 & 3.1 & 2.5 \\
\hline \multirow{2}{*}{$\mathrm{Cr}$} & 283.563 & 0.1 & 0.1 & 1.3 & 1.4 & 2.5 & 2.7 & 2.5 \\
& 284.325 & 0.5 & 0.1 & 1.4 & 1.2 & 2.6 & 3.0 & 3.2 \\
& 357.869 & 0.8 & 2.1 & 0.9 & 0.3 & 2.1 & 2.7 & 2.9 \\
\hline
\end{tabular}

Furthermore, in order to define the recovery of the method, measurements of aqueous solutions and spiked real samples were taken after wet acid digestion. The calculated recovery values of mixed standard aqueous solutions, which ranged between $85.3 \%$ and $104.2 \%$, are represented in Table 6 , along with the recovery values of selected feedstuff samples (AFS-1, AFS-3, AFS-5), which were first spiked with $50 \mathrm{mg}$ of each metal and then with $0.5 \mathrm{mg}$ of each metal, after which each mixture was digested following the digestion procedure described above. The calculated recovery values obtained from the $0.5 \mathrm{mg}$ spiked samples were in agreement with the recovery values obtained from $50 \mathrm{mg}$ spiked samples. The best recovery values for $\mathrm{Cr}$ were calculated at $357.869 \mathrm{~nm}$ both for aqueous and spiked real samples, while the differentiation from the recoveries at the other spectral lines is probably attributable to baseline problems. As regards Ti, at spectral line $334.940 \mathrm{~nm}$, the calculated recoveries were higher in both the aqueous solutions and real samples. 
Table 6. Estimated recovery (R\%) values of the aqueous solutions and spiked feedstuff samples. Mean recovery calculated from $n=3$ measurements.

\begin{tabular}{|c|c|c|c|c|c|c|c|c|}
\hline \multirow[b]{2}{*}{ Element } & \multirow{2}{*}{$\begin{array}{l}\text { Wavelength } \\
\text { (nm) }\end{array}$} & \multirow{2}{*}{$\begin{array}{l}\mathrm{R} \% \text { from } \\
\text { Aqueous } \\
\text { Solutions }\end{array}$} & \multicolumn{2}{|c|}{ R\% of AFS-1 } & \multicolumn{2}{|c|}{ R $\%$ of AFS-3 } & \multicolumn{2}{|c|}{ R\% of AFS- 5} \\
\hline & & & $\begin{array}{c}50 \mathrm{mg} \\
\text { Addition }\end{array}$ & $\begin{array}{c}0.5 \mathrm{mg} \\
\text { Addition }\end{array}$ & $\begin{array}{c}50 \mathrm{mg} \\
\text { Addition }\end{array}$ & $\begin{array}{c}0.5 \mathrm{mg} \\
\text { Addition }\end{array}$ & $\begin{array}{c}50 \mathrm{mg} \\
\text { Addition }\end{array}$ & $\begin{array}{c}0.5 \mathrm{mg} \\
\text { Addition }\end{array}$ \\
\hline \multirow{4}{*}{$\mathrm{Ti}$} & 334.940 & 103.9 & 98.3 & 97 & 103.3 & 99.1 & 93.3 & 90.2 \\
\hline & 336.121 & 89.5 & 79.0 & 75 & 85.0 & 80 & 78.0 & 70.1 \\
\hline & 337.279 & 91.2 & 81.3 & 80 & 86.7 & 83.6 & 79.7 & 75.6 \\
\hline & 368.519 & 89.7 & 79.7 & 74.3 & 84.7 & 80 & 78.0 & 72 \\
\hline \multirow{3}{*}{$\mathrm{Cr}$} & 283.563 & 85.3 & 81.5 & 79 & 80.0 & 74.4 & 76.9 & 72.5 \\
\hline & 284.325 & 86.8 & 81.5 & 79 & 81.5 & 79.2 & 78.5 & 75.8 \\
\hline & 357.869 & 104.2 & 92.3 & 91.1 & 95.4 & 92.5 & 93.8 & 91.4 \\
\hline
\end{tabular}

\subsection{Application to Commercialyl Available Feedstuffs}

The method described above was applied to six different commercially available kinds of dry feedstuff in Thessaloniki, Greece. Before the application of the analytical technique, wet digestion of all samples was required, and the same procedure was performed three times for each sample. Concentration values found for $\mathrm{Cr}$ in non-spiked dry feedstuff samples (after wet digestion), ranged between $0.07( \pm 0.01)$ and $0.18( \pm 0.08) \mathrm{g} \mathrm{kg}^{-1}$. Additionally, Ti concentration for non-spiked feedstuffs ranged between values which were below the LOD of the method, up to $1.35( \pm 0.35) \mathrm{g} \mathrm{kg}^{-1}$. Table 7 shows detailed results for the content of chromium and titanium in spiked (50 $\mathrm{mg}$ of each metal) and non-spiked feedstuffs.

Table 7. Concentration values obtained for total $\mathrm{Ti}$ and $\mathrm{Cr}\left(\mathrm{g} \mathrm{kg}^{-1}\right.$ dry weight), $n=3$.

\begin{tabular}{|c|c|c|c|c|c|c|c|c|c|c|}
\hline \multirow{3}{*}{ Element } & \multirow{3}{*}{$\begin{array}{l}\text { Wavelength } \\
(\mathrm{nm})\end{array}$} & \multicolumn{3}{|c|}{ Dog food } & \multicolumn{3}{|c|}{ Cat Food } & \multicolumn{3}{|c|}{ Poultry Food } \\
\hline & & \multicolumn{2}{|c|}{ AFS-1 } & \multirow[b]{2}{*}{ AFS-2 } & \multicolumn{2}{|c|}{ AFS-3 } & \multirow[b]{2}{*}{ AFS-4 } & \multicolumn{2}{|c|}{ AFS-5 } & \multirow[b]{2}{*}{ AFS-6 } \\
\hline & & $\begin{array}{c}\text { Non } \\
\text { Spiked }\end{array}$ & $\begin{array}{l}\text { Spiked } \\
(50 \mathrm{mg})\end{array}$ & & $\begin{array}{c}\text { Non } \\
\text { Spiked }\end{array}$ & $\begin{array}{l}\text { Spiked } \\
(50 \mathrm{mg})\end{array}$ & & $\begin{array}{c}\text { Non } \\
\text { Spiked }\end{array}$ & $\begin{array}{l}\text { Spiked } \\
(50 \mathrm{mg})\end{array}$ & \\
\hline $\mathrm{Ti}$ & 334.940 & $<\mathrm{LOD}$ & $\begin{array}{c}130.43 \\
( \pm 14.00)\end{array}$ & $<\mathrm{LOD}$ & $\begin{array}{c}0.70 \\
( \pm 0.08)\end{array}$ & $\begin{array}{l}207.79 \\
( \pm 2.4)\end{array}$ & $\begin{array}{c}0.70 \\
( \pm 0.05)\end{array}$ & $\begin{array}{c}0.82 \\
( \pm 0.26)\end{array}$ & $\begin{array}{l}187.35 \\
( \pm 1.90)\end{array}$ & $\begin{array}{c}1.35 \\
( \pm 0.35)\end{array}$ \\
\hline $\mathrm{Cr}$ & 357.869 & $\begin{array}{c}0.10 \\
( \pm 0.01)\end{array}$ & $\begin{array}{c}40.09 \\
( \pm 2.51)\end{array}$ & $\begin{array}{c}0.10 \\
( \pm 0.01)\end{array}$ & $\begin{array}{c}0.18 \\
( \pm 0.08)\end{array}$ & $\begin{array}{c}41.75 \\
( \pm 0.98)\end{array}$ & $\begin{array}{c}0.10 \\
( \pm 0.02)\end{array}$ & $\begin{array}{c}0.07 \\
( \pm 0.01)\end{array}$ & $\begin{array}{c}40.83 \\
( \pm 0.56)\end{array}$ & $\begin{array}{c}0.07 \\
( \pm 0.01)\end{array}$ \\
\hline
\end{tabular}

It was observed that, apart from the samples of dog food, in which the analytes were below the limits of detection of the method, the presence of titanium is noticeable in all other feedstuffs. Chromium was present in all samples. It is worth mentioning that no comparison was made between the results and the product labels, as neither of the metals analyzed in the present study were mentioned in the ingredient lists of the products.

\section{Conclusions}

Titanium is not an essential element for the health and wellbeing of animals, so there is no estimated daily intake for titanium. According to the results of this study, no titanium was found in dog food samples, but in cat and poultry food samples the concentration of Ti ranged from 0.32 to $1.35 \mathrm{~g} / \mathrm{kg}$. On the other hand, chromium is considered an important element for the weight management and the glucose levels of pets $[13,14]$, and the estimated adequate daily intake of chromium is $25-35 \mu \mathrm{g} / \mathrm{day}$ [28]. Chromium concentration levels ranged from 0.07 to $1.10 \mathrm{~g} / \mathrm{kg}$ in the investigated pet food samples. In general, the results of the present study indicate that in common pet foods, either there is no presence of $\mathrm{Cr}$ and $\mathrm{Ti}$ or their concentrations are very low.

In the current study, concentrated nitric and concentrated sulfuric acid were used for wet digestion of the sample, which proved to be an effective and fast process for the recovery of the studied metals. 
The use of $\mathrm{HCl}$ and $\mathrm{H}_{2} \mathrm{O}_{2}$ was not satisfactory because they could not effectively digest the samples under the experimental conditions. Regarding the analytical performance of the applied method, calibration at all the selected spectral lines showed very good correlation coefficients $(>0.999)$. The three spectral lines of $\mathrm{Cr}$ showed similar correlation coefficients, $r=0.9999$, and the spectral line at $357.869 \mathrm{~nm}$ was preferable in terms of sensitivity, considering both its high slope and low intercept. Additionally, the recovery values of the spiked samples ranged between $91.1 \%$ and $104.2 \%$. Regarding $\mathrm{Ti}$, the four spectral lines showed very good correlation coefficients, $r>0.999$, with spectral lines $334.940 \mathrm{~nm}$ and $336.121 \mathrm{~nm}$ being preferable in terms of sensitivity. The suggested spectral line for quantification of $\mathrm{Ti}$ was considered to be $334.940 \mathrm{~nm}$ due to high sensitivity, according to the high slope, and recovery values ranged between $90.2 \%$ and $103.9 \%$. The repeatability of aqueous solutions was better at low concentration levels of the curve, but was also acceptable at high concentrations. Regarding the RSD\% of spiked samples, the calculated values were acceptable for every spectral line. Furthermore, the applied standard addition procedure showed comparable results with the external standard procedure in terms of sensitivity and recovery. In conclusion, the most appropriate spectral line for quantification of $\mathrm{Ti}$ is $334.940 \mathrm{~nm}$ and of $\mathrm{Cr}$ is $357.869 \mathrm{~nm}$, in terms of both sensitivity and detectability. Although in terms of recovery and sensitivity the proposed method is comparable with other fast ones, its main advantage is that it was able to simultaneously determine titanium and chromium with satisfactory detection limits and good analytical characteristics, and was adequate to quantify them if used as external markers.

Author Contributions: Conceptualization and Investigation, G.Z.; Methodology, E.T.; Writing-Original Draft Preparation, E.T.; Writing_-Review \& Editing, G.Z.; Supervision, G.Z. All authors have read and agreed to the published version of the manuscript.

Funding: This research received no external funding.

Conflicts of Interest: The authors declare no conflict of interest.

\section{References}

1. Thompson, A. Ingredients: Where Pet Food Starts. Top. Companion Anim. Med. 2008, 23, 127-132. [CrossRef]

2. Barnett, M.C.; Forster, N.A.; Ray, G.A.; Li, L.; Guppy, C.N.; Hegarty, R.S. Using portable X-ray fluorescence (pXRF) to determine fecal concentrations of non-absorbable digesta kinetic and digestibility markers in sheep and cattle. Anim. Feed Sci. Technol. 2016, 212, 35-41. [CrossRef]

3. Jani, P.; McCarthy, D.; Florence, A. Titanium dioxide (rutile) particle uptake from the rat GI tract and translocation to systemic organs after oral administration. Int. J. Pharm. 1994, 105, 157-168. [CrossRef]

4. Jagger, S.; Wiseman, J.; Cole, D.; Craigon, J. Evaluation of inert markers for the determination of ileal and faecal apparent digestibility values in the pig. Br. J. Nutr. 1992, 68, 129-139. [CrossRef]

5. Titgemeyer, E.C.; Armendariz, C.K.; Bindel, D.J.; Greenwood, R.H.; Loest, C.A. Evaluation of titanium dioxide as a digestibility marker for cattle. Am. Soc. Anim. Sci. 2001, 79, 1059-1063. [CrossRef]

6. Boguhn, J.; Baumgartel, T.; Dieckmann, A.; Rodehutscord, M. Determination of titanium dioxide supplements in different matrices using two methods involving photometer and inductively coupled plasma optical emission spectrometer measurements. Arch. Anim. Nutr. 2009, 63, 337-342. [CrossRef] [PubMed]

7. Myers, W.D.; Ludden, P.A.; Nayigihugu, V.; Hess, B.W. Technical Note: A procedure for the preparation and quantitative analysis of samples for titanium dioxide. Am. Soc. Anim. Sci. 2004, 82, 179-183. [CrossRef] [PubMed]

8. de Souza, J.; Batistel, F.; Welter, K.C.; Silva, M.M.; Costa, D.F.; Santos, F.A.P. Evaluation of external markers to estimate fecal excretion, intake, and digestibility in dairy cows. Trop. Anim. Health Prod. 2015, 47, 265-268. [CrossRef] [PubMed]

9. Myers, W.D.; Ludden, P.A.; Nayigihugu, V.; Hess, B.W. Excretion patterns of titanium dioxide and chromic oxide in duodenal digesta and feces of ewes. Small Rumin. Res. 2006, 63, 135-214. [CrossRef]

10. Janus, M. Titanium Dioxide as Food Additive. In Application of Titanium Dioxide; IntechOpen: London, UK, 2017. 
11. Glindemann, T.; Tas, B.M.; Wang, C.; Alvers, S.; Susenbeth, A. Evaluation of titanium dioxide as an inert marker for estimating faecal excretion in grazing sheep. Anim. Feed Sci. Technol. 2009, 152, 186-197. [CrossRef]

12. Huhtanen, P.; Kaustell, K.; Jaakkola, S. The use of internal markers to predict total digestibility and duodenal flow of nutrients in cattle given six different diets. Anim. Feed Sci. Technol. 1994, 48, 211-227. [CrossRef]

13. Spears, J.W.; Whisnant, C.S.; Huntington, G.B.; Lloyd, K.E.; Fry, R.S.; Krafka, K.; Lamptey, A. Chromium propionate enhances insulin sensitivity in growing cattle. J. Dairy Sci. 2012, 95, 2037-2045. [CrossRef] [PubMed]

14. Vargas-Rodriguez, C.F.; Yuan, K.; Titgemeyer, E.C.; Mamedova, L.K.; Griswold, K.E.; Bradford, B.J. Effects of supplemental chromium propionate and rumen-protected amino acids on productivity, diet digestibility, and energy balance of peak-lactation dairy cattle. J. Dairy Sci. 2014, 97, 3815-3821. [CrossRef]

15. Andrade Korn, M.D.G.; da Boa Morte, E.S.; Batista dos Santos, D.C.M.; Castro, J.T.; Barbosa, J.T.P.; Teixeira, A.P.; Fernandes, A.P.; Welz, B.; dos Santos, W.P.C.; Nunes dos Santos, E.B.G.; et al. Sample Preparation for the Determination of Metals in Food Samples Using Spectroanalytical Methods-A Review. Appl. Spectrosc. Rev. 2008, 43, 67-92. [CrossRef]

16. Oliveira, E. Sample Preparation for Atomic Spectroscopy: Evolution and Future Trends. J. Braz. Chem. Soc. 2003, 14, 174-182. [CrossRef]

17. Santos, W.P.C.; Castro, J.T.; Bezerra, M.A.; Fernandes, A.P.; Ferreira, S.L.C.; Korn, M.G.A. Multivariate optimisation of ICP OES instrumental parameters for $\mathrm{Pb} / \mathrm{Ba} / \mathrm{Sb}$ measurement in gunshot residues. Microchem. J. 2009, 91, 153-158. [CrossRef]

18. da Costa, S.S.L.; Pereira, A.C.L.; Passos, E.A.; Alves, P.J.H.; Garcia, C.A.B.; Araujo, R.G.O. Multivariate optimization of an analytical method for the analysis of dog and cat foods by ICP OES. Talanta 2013, 108, 157-164. [CrossRef]

19. Kelly, D.G.; White, S.D.; Weir, R.D. Elemental composition of dog foods using nitric acid and simulated gastric digestions. Food Chem. Toxicol. 2013, 55, 568-577. [CrossRef]

20. Morgan, N.K.; Scholey, D.V.; Burton, E.J. A comparison of two methods for determining titanium dioxide marker content in broiler digestibility studies. Animal 2014, 10, 1-5. [CrossRef]

21. Miranda, M.; Benedito, J.L.; Blanco-Penedo, I.; Lopez-Lamas, C.; Merino, A.; Lopez-Alonso, M. Metal accumulation in cattle raised in a serpentine-soil area: Relationship between metal concentrations in soil, forage and animal tissues. J. Trace Elem. Med. Biol. 2009, 23, 231-238. [CrossRef]

22. Oliveira, A.F.; Nogueira, A.R.A.; da Silva, C.S.; Silva, C.S. The use of diluted formic acid in sample preparation for macro- and microelements determination in foodstuff samples using ICP OES. J. Food Compos. Anal. 2018, 66, 7-12. [CrossRef]

23. Zachariadis, G.A. Inductively Coupled Plasma Atomic Emission Spectrometry: A Model Multi-Elemental Technique for Modern Analytical Laboratory; Nova Science Publishers: New York, NY, USA, 2011; pp. 18-65.

24. Pedro, N.A.R.; Oliveira, E.; Cadore, S. Study of the mineral content of chocolate flavoured beverages. Food Chem. 2006, 95, 94-100. [CrossRef]

25. Ferreira, H.S.; Santos, A.C.N.; Portugal, L.A.; Costa, A.C.S.; Miro, M.; Ferreira, S.L.C. Pre-concentration procedure for determination of copper and zinc in food samples by sequential multi-element flame atomic absorption spectrometry. Talanta 2008, 77, 73-76. [CrossRef] [PubMed]

26. Batista, B.L.; Rodrigues, J.L.; Souza, S.S.; Souza, V.C.O.; Barbosa, J.R.F. Mercury speciation in seafood samples by LC-ICP-MS with a rapid ultrasound-assisted extraction procedure: Application to the determination of mercury in Brazilian seafood samples. Food Chem. 2011, 126, 2000-2004. [CrossRef] [PubMed]

27. IUPAC. Compendium in Chemical Terminology, Version 2014; Blackwell Scientific Publications: Oxford, UK, 1997.

28. Trumbo, P.; Yates, A.A.; Schlicker, S.; Poos, M. Dietary Reference Intakes for Vitamin A, Vitamin K, Arsenic, Boron, Chromium, Copper, Iodine, Iron, Manganese, Molybdenum, Nickel, Silicon, Vanadium, and Zinc; National Academies Press: Washington, DC, USA, 2001.

(C) 2019 by the authors. Licensee MDPI, Basel, Switzerland. This article is an open access article distributed under the terms and conditions of the Creative Commons Attribution (CC BY) license (http://creativecommons.org/licenses/by/4.0/). 